\title{
Accounting, Culture, And Emerging Economies: IFRS In The BRIC Countries
}

David R. Borker, Ph.D., MAcc., CPA, Manhattanville College, USA

\begin{abstract}
The culturally derived accounting orientations of four major emerging economies, Brazil, Russia, India and China, the BRIC countries, are examined based on the Geert Hofstede work on cultural dimensions (Hofstede, 1980) and the hypothetical derivation of related accounting values by S. J. Gray. (Gray, 1988) Results on Hofstede's four original cultural dimensions are analyzed and compared. An analysis of results for Gray's derived accounting values is presented for these countries. An IFRS favorable profile based on Gray's accounting value dimensions is developed and BRIC and G7 results on these dimensions are compared. Strategies to adjust for country cultural profiles at variance with the IFRS profile are proposed.
\end{abstract}

Keywords: IFRS in BRIC Countries; Accounting Standards in BRIC Countries

\section{INTRODUCTION}

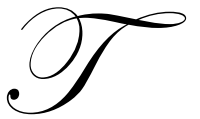

he area of comparative international accounting has developed as a significant focus of accounting research and education since the 1980s. Much of this work consists of studies of the accounting systems of individual countries, with some regional and comparative studies. In the English speaking world, there have been studies of accounting systems and practices of the United States, the United Kingdom, Canada, Australia and New Zealand, both on an individual country basis, and as a related grouping. (Arnold \& Collier, 2007) (Baker \& Quick, 1998) (Billings \& Capie, 2009) (Bloom \& Naciri, 1989) (Lindsay, 1992) (Napier, 1995) There have also been studies of Western European countries, (Diem, 1929) (Emenyonu \& Gray, 1992) (Boerstler, 2006) (Heidhues \& Patel, 2011), the Central and East European countries (Patton \& Zelenka, 1997) (Jermakowicz \& Rinke, 1996) (McGee \& Preobragenskaya, 2006) (Haldma, 2004), Russia and the Commonwealth of Independent States (CIS) (Horwitz, 1963) (Hellström, 2006) (Lebow \& Tondkar, 1986) (Krylova, 2003), Asia-Pacific countries (Hooi, 2007) (Hwang, Staley, Chen, \& Lan, 2008) (Sudarwan \& Fogarty, 1996) (Williams \& Tower, 1998) (Chow, G. K. Chau, \& Gray, 1995) (Chow, Deng, \& Ho, 2000) (Oguri, 2002), and, to a lesser extent, countries in the Middle East and Africa and Central and South America. (HassabElnaby \& Mosebach, 2005) (Buys \& Schutte, 2011) (Noravesh, Dilami, \& Bazaz, 2007) (Lopes, 2006)

During this period, the International Accounting Standards Committee (IASC) was formed in 1973, and begins to be taken more seriously. In 2000, its International Accounting Standards (IAS) were recognized by most of the world's major stock markets. In 2001 the IASC was renamed the International Accounting Standards Board (IASB) and its International Accounting Standards were renamed International Financial Reporting Standards (IFRS) to emphasize that the primary goal of accounting standards is to insure fair and accurate financial reporting by all entities. Growing interest in the adoption of IAS and IFRS led to new studies, both theoretical and empirical, on the accounting systems of developing and emerging economies. The introduction of studies of cultures in relationship to management and accounting orientations and practices, e.g., Hofstede, Gray, etc., has resulted in more than just individual descriptions of national accounting systems, but to truly comparative work based on a defined theoretical underpinning. IFRS issues, such as the importance of disclosure, transparency and accounting professionalism, as well as, the problems of harmonization and convergence of host country and IFRS practices in a world of diversity, has led to a blossoming of scholarship on issues in the global adoption of IFRS. (McGee \& Preobragenskaya, 2003) (Soderstrom \& Sun, 2007) (Khatri \& Master, 2009) (Borker, 2012) An important factor in explaining and predicting the relative ease or difficulty a country may have in successfully adopting IFRS and its orientation toward accounting is to examine that culture's own implicit accounting orientation based upon measurable cultural values or dimensions. 
The focus of this paper is an analysis of the culturally derived accounting orientations of four major emerging economies based on the work on cultural dimensions of Geert Hofstede and the hypothetical derivation of related accounting values by S. J. Gray. The four emerging economies studied are Brazil, Russia, India and China comprising what has been defined as the BRIC countries. (Hofstede, 1980) (Hofstede, 2001) (Hofstede, Hofstede, \& Minkov, 2010) (Gray, 1988)

\section{BACKGROUND AND PRIOR RESEARCH}

Emerging economies can be defined as "low-income, rapid-growth countries using economic liberalization as their primary engine of growth" and generally can be classified as either developing countries in Asia, Latin America, Africa and the Middle East or as transition economies as in China or the former Soviet Union. (Hoskisson, Eden, Lau, \& Wright, 2000)

The emerging economies Brazil, Russia, India and China, were first identified as the BRIC countries in 2001 by Jim O'Neill, chairman of Goldman Sachs, in a paper entitled Building Better Economic BRICs. (O'Neill, 2001) O'Neill identified these four economies as most likely to enjoy sustained high growth and to become the ascendant economies during this century. The BRIC countries are often paired into two grouping: Brazil/Russia and India/China. Brazil and Russia are identified as large land mass countries with relatively low populations that are rich in exploitable and exportable natural resources. India and China are characterized as having the world's two largest populations with China expected to be ascendant in manufacturing due to its strong industrial infrastructure and India expected to expand in the service sector in part due to its lack of the same.

All the BRIC countries have committed to the adoption of IFRS, but, except for Brazil, their progress trails the EU countries and many others. With regard to IFRS status, the world's countries can be divided into three categories: (1) those that have already adopted mandatory IFRS, (2) those that have set up a time frame for adoption, and (3) those who have no full plan in place. Brazil is in Category1, having required IFRS reporting for banks and listed companies from December 2010, and for individual company accounts progressively since 2008. Russia, China and India all are Category 2. Russia has required IFRS reporting for banks since 2008, and plans to require IFRS reporting for consolidated companies in 2013 for fiscal 2012 results. However, many public companies that are cross border traded already voluntarily produce IFRS financial statements. Convergence has proved to be a slow game of catch-up, as IFRS continue to evolve, and Russia is planning for full IFRS adoption. (Borker, 2012) China has substantially converged its national accounting with IFRS, but has not made IFRS fully mandatory. (McGregor, 2006) (Financial_Standards_Foundation, 2008) India issued IFRS-converged Indian Accounting Standards (IndAS) in February 2011, but Indian regulators have postponed implementing the new converged standards until April 2012. They attribute this postponement to the lack of resolution on taxation issues. It is possible that all regulatory steps required to implement IndAS can be completed over the next several months so that IndAS can become mandatory from April 2012. However, subsequent changes in IFRS in 2013 would require further changes in IndAS and further delay of the realization of world standard IFRS reporting until much later. (Khatri J., 2011)

It is common wisdom that accelerated adoption/convergence with IFRS is a high priority for BRIC countries due to their need for continued capital infusion to sustain their high economic growth and the prospect that it may help to increase market liquidity and reduce individual companies cost of capital. Further, firms that perceive high economic incentives are more likely to achieve a higher level of compliance with IFRS in their financial reporting. Brazil, which has made the most progress in IFRS, has also pursued a monetary policy of allowing the BRL to appreciate against other currencies in order to attract investors, in spite of the fact that the stronger BRL may reduce its level of exports. Interestingly, post IFRS adoption research indicates that IFRS has increased market liquidity in Brazil and Brazilian firms with high economic incentives have achieved a higher level of compliance with IFRS in their financial reporting. However, research did not find a statistically valid connection between IFRS and lower cost of capital (Lima, Sampaio, De Lima, de Cavallio, \& Lima, 2010)

Gray's creative association of accounting values based on relationships to Hofstede's cultural dimensions (Hofstede, 1980) is founded on the argument that culture influences accounting. This stems from the general notion that societal values lead to the development and maintenance of institutions within a society, including educational, social, and political systems, as well as, legal, financial, and corporate structures. Once in place, these systems 
reflect and reinforce societal values and tend to be stable and remain in place with changes at the national level occurring primarily due to major external factors, such as international trade, investment, multinational companies, and colonization. (Gray, 1988)

In his early research, Geert Hofstede (Hofstede, 1980) identified four measurable cultural dimensions that differentiate cultures. The data upon which these dimensions were originally developed came from pencil and paper survey results collected within one large multinational business organization (IBM) in 72 countries. Later, surveys had a more diverse base. The four dimensions identified are

1) Individualism versus collectivism (IDV), the relationship between the individual and the group,

2) Power distance (PDI), social inequality including relationships with authority,

3) Masculinity versus femininity (MAS), social implications of being born male or female,

4) Uncertainty avoidance (UAI), the ability to deal with uncertainty, the control of aggression and the expression of emotion.

Since that time, Hofstede and his associates have introduced two additional cultural dimensions. (Hofstede, 2001) (Hofstede, Hofstede, \& Minkov, 2010) These are:

5) Long-term orientation versus short-term orientation (LTO)

6) Indulgence versus restraint (IVR)

Extending the concepts of Hofstede's original four dimensions to accounting, Gray suggests that accounting values are derived from such cultural dimensions, which in turn influence accounting systems. Gray identifies four key accounting values or dimensions.

1) Professionalism versus statutory control, referring to professional judgment and self-regulation in contrast to compliance with rigid legal requirements and legislative control,

2) Uniformity versus flexibility, the level of enforcement of standardized and consistent accounting practices,

3) Conservatism versus optimism, a vigilant approach to accounting measurement, as opposed to a more optimistic and risk-taking approach,

4) Secrecy versus transparency, confidentiality and the constraint of disclosure of information, as opposed to a more transparent and publicly accountable approach. (Gray, 1988)

Considering this interaction between the Hofstede cultural dimensions, and his own accounting values, Gray offered the following hypotheses. (Gray, 1988)

H1: The higher a ranking in terms of individualism and the lower the ranking in terms of uncertainty avoidance and power distance, the more likely the country is to rank highly in terms of professionalism.

H2: The higher a ranking in terms of uncertainty avoidance and power distance and the lower the ranking in terms of individualism, the more likely it is to rank highly in terms of uniformity.

H3: The higher a ranking in terms of uncertainty avoidance and the lower the ranking in terms of individualism and masculinity, the more likely it is to rank highly in terms of conservatism.

H4: The higher a ranking in terms of uncertainty avoidance and power distance and the lower the ranking in terms of individualism and masculinity, the more likely it is to rank high in terms of secrecy.

Elements of the above hypotheses can be summarized in table format where each of the Gray accounting values are rows and each of Hofstede's dimensions are columns. In accordance with the Gray hypotheses, cells in the table are populated using the following notations direct (+), indirect (-), or undetermined correlation to one another (?). (Chanchani \& MacGregor, 1999) Where a specific dimension is identified by Gray as having a stronger correlation, a double plus $(++)$ or double minus (- -$)$ is used. The undetermined correlation (?) indicates that Gray has not made any connection between that Hofstede dimension and the specific accounting value. Table 1 below shows this summary. 
Table 1: Hofstede-Gray Correlations

\begin{tabular}{|l|c|c|c|c|}
\hline & Power Distance & Individualism & Masculinity & Uncertainty Avoidance \\
\hline Conservatism & + & - & - & ++ \\
\hline Uniformity & + & -- & $?$ & ++ \\
\hline Professionalism & - & ++ & $?$ & -- \\
\hline Secrecy & ++ & -- & - & ++ \\
\hline
\end{tabular}

\section{BRIC COUNTRIES: HOFSTEDE AND GRAY RESULTS AND ANALYSIS}

\section{PART I: Hofstede cultural dimensions of BRIC countries}

The cultural dimension index values of the BRIC countries are presented in Table 2. Definitions and discussion of the dimensions of each BRIC country in the section that follows are taken directly from Hofstede. (Hofstede, 2001) (Hofstede, Hofstede, \& Minkov, 2010) Analytical statements comparing the BRIC countries within each dimension are those of the author.

Table 2: Index Rating: Cultural Dimensions for BRIC Countries

\begin{tabular}{|l|c|c|c|c|}
\hline & Brazil & Russia & India & China \\
\hline Individualism (IDV) & 38 & 36 & 48 & 20 \\
\hline Power Distance (PDI) & 69 & 93 & 77 & 80 \\
\hline Masculinity vs. Femininity (MAS) & 49 & 36 & 56 & 66 \\
\hline Uncertainty Avoidance (UAI) & 76 & 95 & 40 & 40 \\
\hline
\end{tabular}

\section{Individualism (IDV)}

In his writings, Hofstede defines the fundamental issue addressed by this dimension as the degree of interdependence a society maintains among its members. Societies and cultures with a preference for individualism also tend to have preference for a loosely knit social framework. (Hofstede, Hofstede and Minkov 2010)

Brazil has a score which means that in this country people from birth onwards are integrated into strong, cohesive groups, especially represented by the extended family, e.g., uncles, aunts, grandparents and cousins. Protection of the group members is performed in exchange for loyalty. In business interactions, it is important to build up a trustworthy and long lasting relationship. A business interaction meeting usually starts with general conversations before doing business. The preferred communication style is context-rich, so people will often speak profusely and write in an elaborate fashion. Russia also has a lower score similar to Brazil. Family, friends and often neighbors are extremely important to getting through the challenges of everyday life. Relationships are crucial in obtaining information, getting critical introductions and completing successful negotiations. Relationships need to be personal, authentic and full of trust before one begins to focus on tasks. India falls in the middle between individualism and collectivism. This may have many roots, including the lingering influence of being part of the British Commonwealth for several hundred years. Wide spread entrepreneurship and India's phenomenal growth of a professional technology class may also contribute. Further, India is not dominated by one monolithic political ideology or religion, leaving room for pluralistic, individualistic thinking. China, with its much lower score, the lowest of the BRIC set of countries, is a highly collectivist culture where people act in the interests of the group rather than themselves. In-group considerations affect hiring and promotions in business, with family often get preferential consideration. Employee commitment to the organization is low, whereas relationships with colleagues are cooperative for in-groups. Personal relationships prevail over task and company. (Hofstede, Hofstede and Minkov 2010)

Considering the index values for the BRIC countries as a whole, individual rights, as measured by individualism, are more dominant for India than for the others in this group. 


\section{Power Distance (PDI)}

Power distance is defined as the extent to which the less powerful members of institutions and organizations within a country expect and accept that power is distributed unequally. Cultures with lower index scores on PDI aim for power equalization and demand justification for power inequalities. (Hofstede, Hofstede and Minkov 2010)

Brazil reflects a society that believes hierarchy should be respected and inequalities among people are acceptable. The different distribution of power justifies the fact that power holders have more benefits than the less powerful in society. Status symbols of power are very important since they indicate social position and where respect should be shown. Russia is among the $10 \%$ of the most power distant societies in the world. It is extremely centralized with more than two-thirds of all foreign investments going into Moscow where $80 \%$ of all financial potential is concentrated. Behavior must reflect and represent the status roles in all areas of business interactions, e.g., visits, negotiations, cooperation, etc. A top-down approach is clearly mandated for any and all tasks. India also is among the higher rankings on PDI. It is a society in which there is a tradition of trans-generational inequities due to traditional social castes. People are accustomed to contrasts of extreme wealth and frequent poverty. China has a score that is in the highest rankings of any country on PDI. China is a society that believes that inequalities among people are acceptable. The subordinate-superior relationship tends to be polarized and there is no defense against power abuse by superiors. Individuals are influenced by formal authority and sanctions, and in general are optimistic about people's capacity for leadership and initiative. People are not to have aspirations beyond their rank.

All of the BRIC countries have scores well above the average on PDI. That is, all the BRIC countries have cultural values that are, to a greater or lesser extent, accepting of the inequalities of a society where there is great distance between the rich and powerful and the poor.

\section{Masculinity vs. Femininity (MAS)}

The fundamental issue in the MAS dimension is what motivates people, i.e. wanting to be the best (masculine) or wanting others liking what you do (feminine). A masculine score on this dimension indicates that the country in question is driven by competition, achievement and success. This is defined by being the winner or the best in the field. A feminine score on the dimension means that the dominant values in society are caring for others and quality of life. Societies with high masculinity ratings value attributes such as income, recognition and advancement, while feminine dimensions include a preference for putting relationships with people before money, helping others, caring for the weak, quality of life and the preservation of the environment. (Hofstede, Hofstede and Minkov 2010)

Brazil scores in the middle on this dimension. The softer aspects of culture such as leveling with others, consensus, sympathy for the underdog, and the like, are valued and encouraged. Conflicts are avoided in private and work life. In the end, consensus is most important. Russia scores relatively low on the MAS dimension. In the workplace, as well as when meeting a stranger, Russians understate their personal achievements, contributions or capacities and speak modestly about themselves. Dominant behavior might be accepted when it comes from the boss, but is not appreciated among peers. India's somewhat masculine oriented score suggests a success orientation. This, combined with openness to individualism and risk tolerance, indicates favorable conditions for the growth of entrepreneurs, and of highly skilled and creative professionals, e.g. computer technology specialists. China is a masculine society - success oriented and driven. The need to ensure success can be exemplified by the fact that many Chinese will sacrifice family and leisure priorities to work. Leisure time is not so important. The migrant farmer workers will leave their families behind in faraway places in order to obtain better work and pay in the cities. Chinese students also care very much about their exam scores and ranking as this is the main criterion to achieving success. (Hofstede, Hofstede and Minkov 2010)

The BRIC countries are divided on this dimension, with China and India on the higher end, and Brazil and Russia on the lower. This is consistent with the notion that India and China are projected to succeed on their values of success and business growth, while Brazil and Russia on their existing troves of natural resources. 


\section{Uncertainty Avoidance (UAI)}

The dimension Uncertainty Avoidance has to do with the extent to which the members of a culture feel threatened by ambiguous/ unknown situations, and have created beliefs and institutions that try to avoid these feelings. Low uncertainty avoidance is an indication that members of a society feel secure and will not attempt to control the future through laws. In addition, different ideas and viewpoints will be more easily tolerated, as will willingness to take risk. A high score on this dimension indicates a preference for extensive and rigid rules to decrease uncertainty. (Hofstede, Hofstede and Minkov 2010)

Brazil scores high on UAI, as do the majority of Latin American countries. These societies show a strong need for rules and elaborate legal systems to structure life. In Brazil, bureaucracy, laws and rules are very important. Scoring high on this dimension suggests that Brazilians are a very passionate and demonstrative people. Russia scores very high on the UAI dimension indicating that its people often feel threatened by ambiguous situations. Detailed planning and briefings are very common. Russians prefer to have much context and background information. As long as they interact with those considered to be strangers, formality and distance is the norm. India has a low score on uncertainty avoidance. Indians are comfortable with ambiguity and are adaptable, making them more suited for work in entrepreneurial enterprises and in micro to small sized businesses. After a long period of high taxes and protective tariffs, India has simplified its commercial laws to allow freer trade, resulting in increased foreign expansion, investment, and greatly improved economic growth. China has a low score on uncertainty avoidance. The Chinese are comfortable with ambiguity. This is evident even in the Chinese language, which is full of ambiguous meanings that can be difficult for westerners to comprehend. The Chinese people are adaptable and entrepreneurial. Currently, the majority of Chinese businesses are small to medium sized and family owned. (Hofstede, Hofstede and Minkov 2010)

The pairing of Russia and Brazil versus China and India forms the same pattern as that on the MAS dimension only reversed in low versus high index scores. The pattern of high entrepreneurial and small or family businesses in India and China is consistent with the growth patterns expected of these BRIC countries to blossom into the largest goods (China) and services (India) country by 2050.

\section{PART II: Gray's accounting value dimensions and BRIC countries}

This section discusses the extension of the cultural dimensions identified in the first phase to the accounting value dimensions proposed by Gray to explain and predict the development of different accounting systems (Gray, 1988).

\section{H1 and H2: Professionalism versus Statutory Control / Uniformity versus Flexibility}

Gray's first hypothesis posits that a higher ranking in terms of individualism (IDV) and a lower ranking in terms of uncertainty avoidance (UAI) and power distance (PDI) are indicative of a preference for professionalism. His second hypothesis posits that higher uncertainty avoidance (UAI) and power distance (PDI) rankings, and a lower individualism (IDV) ranking are indicative of a preference for uniformity. It should be noted that Gray indicates that both the professionalism and uniformity accounting dimensions can be linked most closely with Hofstede's individualism and uncertainty avoidance cultural dimensions, while the power distance dimension is seen as less important (Gray, 1988). The results of these two hypotheses in the context of the BRIC country analysis are presented below in Chart 1.

Both Russia and China fully display Gray's patterns for statutory control and uniformity, with Russia exhibiting each to a higher degree. India and China deviate from these patterns due to low rankings for uncertainty avoidance. Both sit somewhere between professionalism versus statutory control, and flexibility versus uniformity due to high power distance. However, India, with the highest individualism in the BRIC group, comes closest to professionalism and flexibility within the group. 


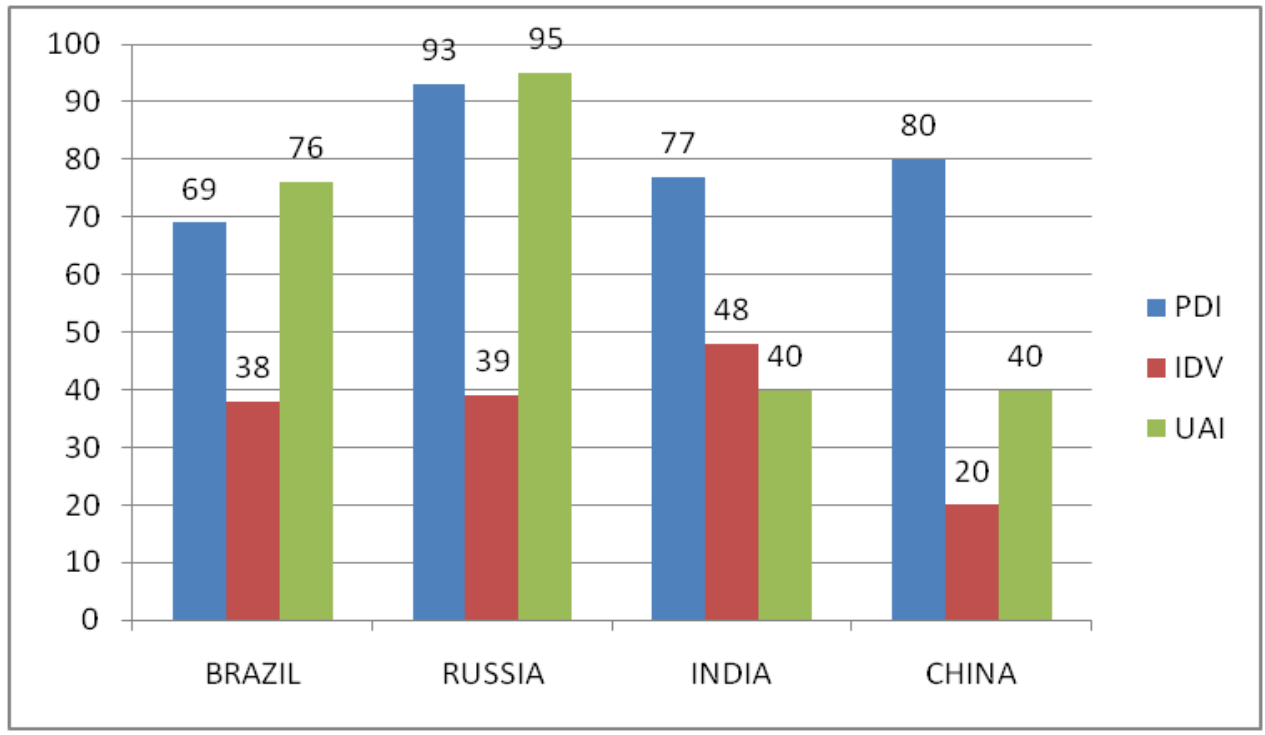

Chart 1: Professionalism vs. Statutory Control / Uniformity vs. Flexibility

\section{H3: Conservatism vs. Optimism}

Gray's third hypothesis posits that higher uncertainty avoidance (UAI), and lower individualism (IDV) and masculinity (MAS) are indications of a preference for conservatism. He suggests that the conservatism accounting dimension can be linked most closely with Hofstede's uncertainty cultural dimension, while masculinity and individualism are seen as less important (Gray, 1988). The results pertaining to cultural dimensions relevant to the accounting values of conservatism and optimism for BRIC countries are presented in Chart 2.

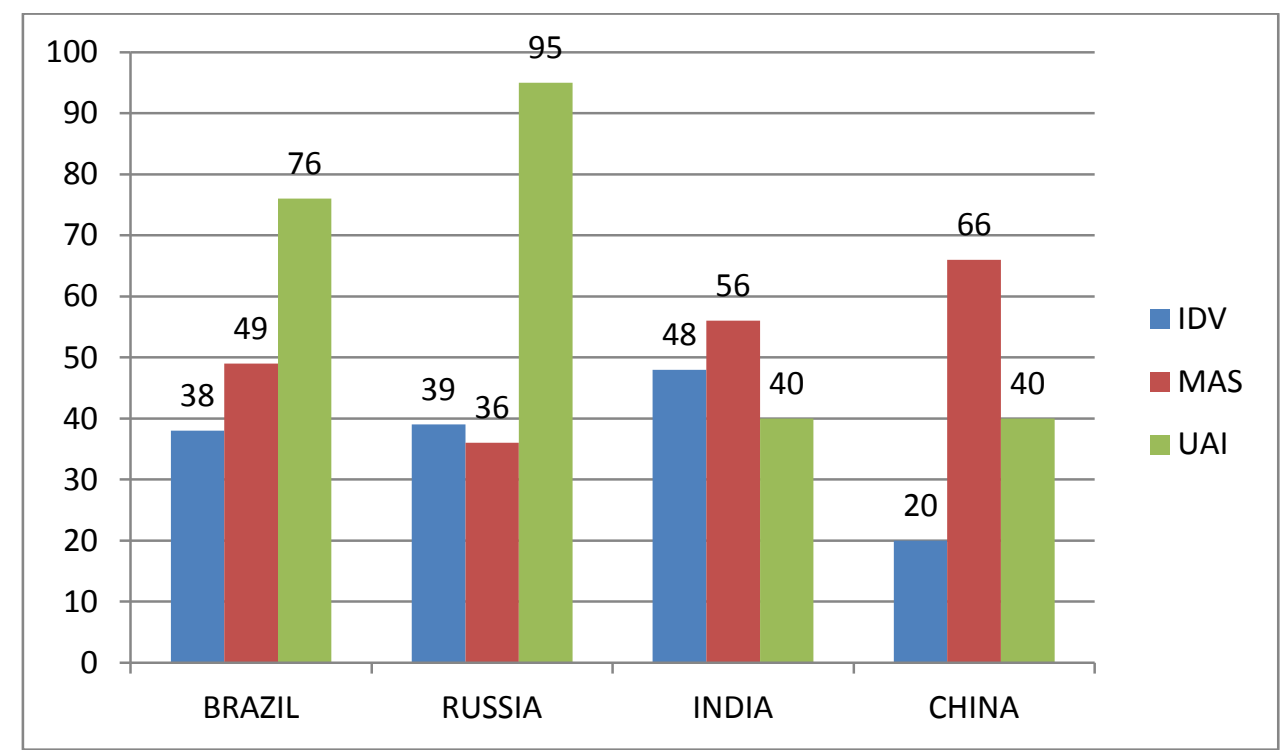

Chart 2: Conservatism vs. Optimism

Russia and Brazil display Gray's full pattern for conservatism, with Russia exhibiting it to a higher degree. China and India deviate from this pattern due to low uncertainty avoidance and high masculinity. India comes closest to the optimism dimension due to having the highest individualism ranking in BRIC, while China is more in the middle due to its very low ranking for individualism. 


\section{H4: Secrecy versus Transparency}

Gray's fourth hypothesis posits that a higher ranking in terms of uncertainty avoidance (UAI) and power distance (PDI), and a lower ranking in terms of individualism (IDV) and masculinity (MAS) is indicative of a preference for secrecy. He indicates that the secrecy accounting dimension can be linked most closely with Hofstede's uncertainty avoidance, power distance and individualism cultural dimensions, while masculinity is seen as less important (Gray, 1988). The results pertaining to the cultural dimensions relevant to the accounting values of secrecy and transparency for the BRIC countries are presented in Chart 3.

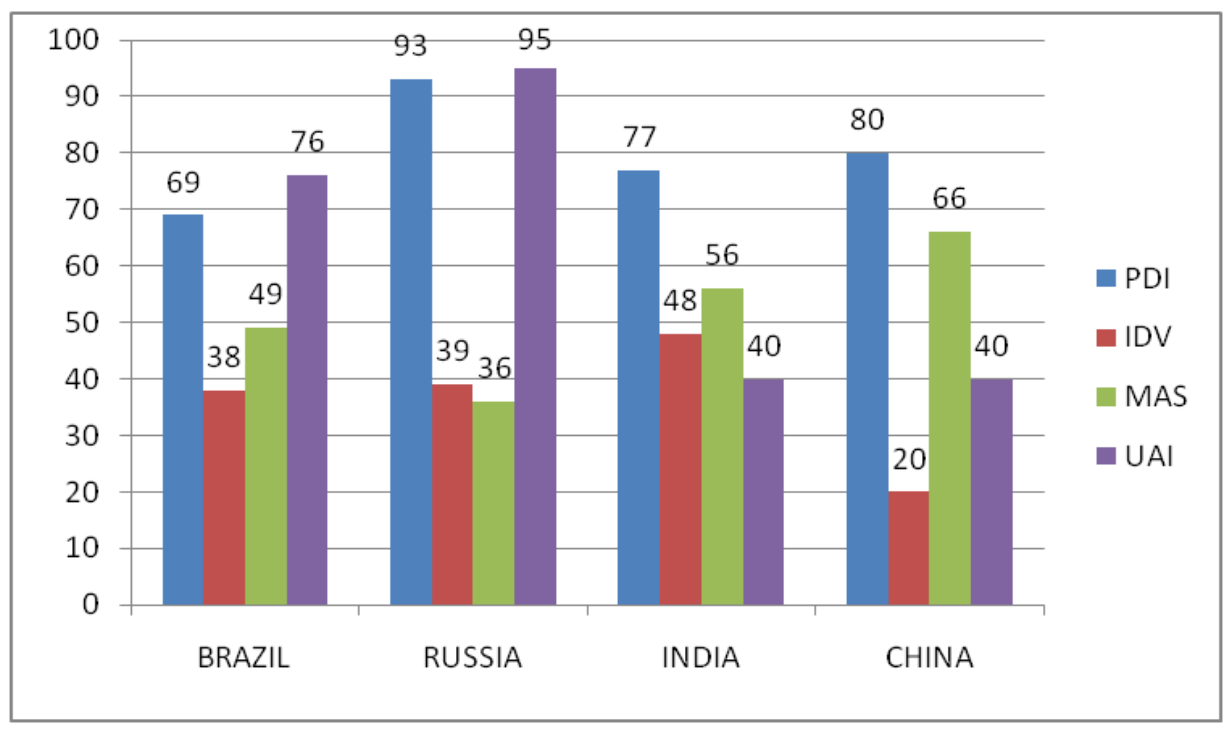

Chart 3: Secrecy vs. Transparency

Both Russia and China display fully Gray's pattern for secrecy, with Russia exhibiting this tendency to a higher degree. India and China deviate from Gray's secrecy pattern due to both low uncertainty avoidance and relatively high masculinity. Although both China and India do exhibit high power distance, their total configuration puts them closer to transparency than either Russia or Brazil.

\section{DISCUSSION}

In order to review and evaluate the results of the above analysis, it is necessary to return to the basic intension of Gray's four hypotheses and his accounting value dimensions. These dimensions are not designed to identify positive versus negative influences on accounting. Rather, Gray's dimensions characterize different contrasting aspects of accounting values that can affect the development of accounting systems in different directions. Each value can be seen as reflecting both advantages and disadvantages associated with systems of accounting. Conservatism is acknowledged as an old and venerated accounting value associated with care, caution and prudence. At the same time, it leaves little room for creativity or new ways of solving reporting problems.

If one looks back to the many national accounting systems that precede IFRS, it is clear that accounting systems can be found that reflect one or the other side of each of Gray's dimensions and, no doubt, many variations in between. For example, continental accounting in Germany and France was characterized by emphasis on statutory control, uniformity, conservatism and secrecy, reflecting the extent to which financing came from large banks rather than equity investors. (Boerstler, 2006) In contrast, what Grays terms the 'Anglo and Nordic culture' of the United States, United Kingdom, Canada and Australia is characterized by emphasis on professionalism, flexibility, transparency, and optimism. (Gray, 1988) This orientation leans more heavily toward private investors rather than financial insiders. 
An objective of this paper is to identify those accounting value dimensions most linked with IFRS and to compare them with the results from the BRIC analysis. IFRS appear to be derived historically from U.S. GAAP and it is perhaps not a total coincidence that the Financial Standards Accounting Board (FASB) and the International Accounting Standards Board (IASB) have such similar names and were both established in 1973. The dimensional profile most consistent with IFRS is that of the Anglo-Nordic cultures which emphasizes the role of the individual professional rather than a more legalistic system stressing uniformity. A proposed representation of the IFRS value profile is shown in Table 3.

Table 3: IFRS Value Profile Based on Gray's Accounting Dimension Hypotheses

\begin{tabular}{|l|l|}
\hline & Dimension(s) \\
\hline H1 & Professionalism \\
\hline H2 & Flexibility \\
\hline H3 & Optimism or Optimism/Conservatism \\
\hline H4 & Transparency \\
\hline
\end{tabular}

The countries with Gray derived value indices closest to the IFRS profile in the major developed countries (G7) are the United States, the United Kingdom and Canada. See Table 4 below. All three of these display all of the indices for professionalism, flexibility, optimism and transparency. The other four G7 members, i.e., Germany, France, Italy, and Japan, all exhibit value sets that diverge to a greater or lesser degree from the IFRS profile in one area or another.

Table 4 - Accounting Values for the G7 Developed Countries Based on Gray's Accounting Dimension Hypotheses

\begin{tabular}{|l|c|c|c|c|c|}
\hline & $\begin{array}{c}\text { U.S.A., U.K., } \\
\text { Canada }\end{array}$ & Germany & France & Italy & Japan \\
\hline H1 & Professionalism & $\begin{array}{c}\text { Professionalism/ } \\
\text { Statutory Control }\end{array}$ & $\begin{array}{c}\text { Statutory Control/ } \\
\text { Professionalism }\end{array}$ & $\begin{array}{c}\text { Professionalism/ } \\
\text { Statutory Control }\end{array}$ & Statutory Control \\
\hline H2 & Flexibility & $\begin{array}{c}\text { Flexibility/ } \\
\text { Uniformity }\end{array}$ & Uniformity/ Flexibility & $\begin{array}{c}\text { Flexibility/ } \\
\text { Uniformity }\end{array}$ & Uniformity \\
\hline H3 & Optimism & $\begin{array}{c}\text { Conservatism/ } \\
\text { Optimism }\end{array}$ & Conservatism & $\begin{array}{c}\text { Conservatism/ } \\
\text { Optimism }\end{array}$ & Conservatism \\
\hline H4 & Transparency & $\begin{array}{c}\text { Transparency/ } \\
\text { Secrecy }\end{array}$ & Secrecy/ transparency & $\begin{array}{c}\text { Transparency/ } \\
\text { Secrecy }\end{array}$ & Secrecy \\
\hline
\end{tabular}

Reviewing the analysis of the BRIC countries for Gray's four hypotheses in Table 5, it can be seen that Russia and Brazil have cultural values that, excluding outside influences, seem to foster accounting values directly opposite to those associated with IFRS. In contrast, India and China exhibit cultural values and derived accounting values that are to a greater degree consistent with the values associated with IFRS. India seems to be somewhat closer to IFRS values than China, but both are markedly different than Russia and Brazil.

Table 5 - Accounting Values for the BRIC Countries Based on Gray's Accounting Dimension Hypotheses

\begin{tabular}{|l|c|c|c|c|}
\hline & Brazil & Russia & India & China \\
\hline H1 & Statutory Control & Statutory Control & $\begin{array}{c}\text { Professionalism/Statutory } \\
\text { control }\end{array}$ & Statutory Control/ Professionalism \\
\hline H2 & Uniformity & Uniformity & Flexibility/Uniformity & Uniformity/Flexibility \\
\hline H3 & Conservatism & Conservatism & Optimism/ Conservatism & Optimism/ Conservatism \\
\hline H4 & Secrecy & Secrecy & Transparency/Secrecy & Transparency/Secrecy \\
\hline
\end{tabular}

Comparing the Gray Hypothesis for BRIC (Tables 4) and G7 countries (Table 5), the following observations arise. Brazil and Russia are similar to one another and to Japan. India is most similar to Germany and Italy. The pattern for China is like none of the G7 countries. 


\section{CONCLUSION}

Applying Gray's four hypotheses to Brazil, Russia, India and China demonstrates that Russia and Brazil have greater similarities to one another than to India and China on matters of disclosure. Specifically, Russia and Brazil exhibit cultural values associated with the development of accounting systems characterized by statutory control, uniformity, conservatism, and secrecy. This is opposite from the values proposed to represent the profile for IFRS, i.e., professionalism, flexibility, optimism and transparency. In the case of India and China, results from both countries for the Gray hypotheses are closer to what we call the IFRS value profile. However, neither reflects values entirely consistent with IFRS. All four of the BRIC countries exhibit higher power distance indices than all the G7, except France.

It is important to note that all of the G7 countries are currently reporting using IFRS, at least for their public stock companies. The Gray cultural dimensions for accounting are designed to predict what kind of accounting systems may develop in a country operating independent of any external influences. It does not take into consideration what can happen if countries are strongly motivated to adopt and conform to IFRS in order to foster better cross-border trade and capital flows in an increasingly global economy. Nonetheless, countries with cultural accounting values more remote from the IFRS value profile may have more to overcome in adopting and continuing to evolve with IFRS, since, by their nature, IFRS tends to evolve and adapt to changes in the nature of business transactions over time. In addition to the issues any nation encounters in the complex process of IFRS adoption, Russia and Brazil, and, to a lesser extent, India and China have a few specific cultural obstacles to overcome.

Countries with cultural/accounting values that are more remote from IFRS could find it useful to utilize a variety of ameliorating strategies to adopt and maintain accounting values supportive of IFRS, such as the following:

- $\quad$ Establish culturally sensitive education and professional training programs

- $\quad$ Establish culturally focused upgrade programs for existing accounting professionals

- Empower national accounting standard setting bodies to integrate the values of professionalism, flexibility, optimism and transparency into their professional activities

- $\quad$ Set realistic timeframes and deadlines for the transition to IFRS to allow the local accounting culture to catch up with new IFRS reforms

- Establish a comprehensive change management program for accounting professionals, businesses, government and the public with the necessary change management tools to make a successful transition.

- $\quad$ Create robust support infrastructures for IFRS implementation. (Borker, 2012)

Some of these strategies are being applied in countries transitioning to IFRS, particularly where the transition involves moving from relatively different accounting cultures. In the case of Russia, there have been serious efforts made to improve the professional and standard setting infrastructure which have been supported by the government and large international accounting firms.

It is significant that Brazil, in spite of its cultural profile based on Hofstede and Gray, appears to have made the most progress in its convergence with IFRS. Clearly, the economic incentives of IFRS as a means to attract foreign investor capital have provided Brazilian firms with the necessary impetus to do what is necessary to assure IFRS compliance. Cultural orientation with respect to accounting systems is only one of many factors that determine a country's success in implementing IFRS. Nevertheless, awareness of cultural orientation helps governments, firms and accounting organizations anticipate challenges and opportunities in coping with change.

\section{AUTHOR INFORMATION}

David Borker holds a $\mathrm{PhD}$ from Yale, Master of Accounting/MBA from Ohio State University and A.B. from Cornell. Dr. Borker is well suited for research in international accounting and business. A native speaker of English, he is fluent in Russian, German and Czech and uses numerous other languages in his research. Dr. Borker has extensive experience as an academic, consultant and a businessman working in Russia, Eastern Europe and the CIS. He teaches accounting, management and international business at Manhattanville College and is a licensed CPA. E-mail: David.Borker@mville.edu 


\section{REFERENCES}

1. Arnold, A., \& Collier, P. (2007). The Evolution of Reserve and Provision Accounting in the UK, 19381950. Edinburg: Edinburg Institute of Chartered Public Accountants of Scotland.

2. Baker, C., \& Quick, R. (1998). Regulating the Auditing Profession: A comparison of the United Kingdom and Germany. Accounting Forum, 22(2), 275-296.

3. Billings, M., \& Capie, F. (2009). Transparency and Financial reporting in mid-20th Century British Banking. Accounting Forum, 33(1), 38-53.

4. Bloom, R., \& Naciri, M. (1989). Accounting Standard Setting and Culture: A comparative Analysis of the United States, Canada, England, West Germany, Australia, New Zealand, Sweden, Japan and Switzerland. The International Journal of Accounting, 24(1), 70-97.

5. Boerstler, C. (2006). Zur Zukunft der externen Rechnungslegung in Deutschland. Wiesbaden: Deutscher Universitaets-Verlag.

6. Borker, D. R. (2012). Stepped-Up Progress On IFRS In Russia: History In The Making. International Business \& Economics Research Journal, 11(2), 255-268.

7. Buys, P., \& Schutte, D. (2011). A Consideration of IFRS Education and Acceptance from Culturally Diverse Backgrounds: A South African Perspective. International Business \& Economics Research Journal, 10(12), 49-58.

8. Chanchani, S., \& MacGregor, A. (1999). A Synthesis of Cultural Studies in Accounting. Journal of Accounting Literature, 18, 10.

9. Chow, L. M., G. K. Chau, \& Gray, S. (1995). Accounting Reforms in China: Cultural Constraints on Implementation. Accounting and Business Research, 26(1), 29-49.

10. Chow, W., Deng, F., \& Ho, J. (2000). The openness of knowledge sharing within organizations: A Comparative Study in the United States and the People's Republic of China. Journal of Management Accounting Research, 12, 65-95.

11. Diem, E. v. (1929). The Development of Professional Accounting in Continental Europe. The Accountant, 409-448.

12. Emenyonu, E., \& Gray, S. (1992). EC Accounting Harmonisation: An Empirical Study of Measurement Practices in France, Germany and the UK. Accounting and Business Research, 23(89), 49.

13. Financial_Standards_Foundation. (2008). BestPractice Report - China. Retrieved May 26, 2009, from http:/www.estandardsforum.org/servlet/PrintPDFReport?country id=5

14. Gray, S. J. (1988). Towards a Theory of Cultural Influence on the Development of Accounting Systems Internationally. Abacus, 24(1), 9-11, 12.

15. Haldma, T. (2004). Development of the Estonian Accounting Policy within the European Framework. In Policy Perspectives of Estonia in the Europan Union (pp. 544-555). Tartu. Estonia: University of Tartu.

16. HassabElnaby, H., \& Mosebach, M. (2005). Culture's Consequences in Controlling Agency Costs: Egyptian Evidence. Journal of International Accounting, Auditing and Taxation, 14(1), 19-32.

17. Heidhues, E., \& Patel, C. (2011). A Critique of Gray's Framework on accounting Values Using Germany as a Case Study. 22(3), 273-287.

18. Hellström, K. (2006). The Value Relevance of Financial Accounting Information in a Transition Economy: The Case of the Czech Republic. European Accounting Review, 15(3), 325-349.

19. Hofstede, G. (1980). Cultures Consequences: International Differences in Work Related Values. Newbury Park, NJ: Sage.

20. Hofstede, G. (2001). Culture's Consequeces: Comparing Values, Behaviors, Institutions, and Organizations acrossNations (2 ed. ed.). Thousand Oaks, London, New Delhi: Sage Publications.

21. Hofstede, G., Hofstede, G. J., \& Minkov, M. (2010). Cultures and Organizations: Software of the Mind: Intercultural Cooperation and its Importance for Survival. New York: McGrawHill.

22. Hooi, G. (2007). The Effects of Culture On International Banking Disclosure. Asia Pacific Journal of Accounting and Ecopnomics, 14(1), 7-25.

23. Horwitz, B. (1963). Depreciation and Cost Stability in Soviet Accounting. The accounting review, 38(4), 819-826.

24. Hoskisson, R. E., Eden, L., Lau, C. M., \& Wright, M. (2000). Strategy in Emerging Economies. Academy of Management Jouirnal, 43(3), 249-267. 
25. Hwang, D., Staley, B., Chen, Y., \& Lan, J. (2008). Confucian Culture and Whistle Blowing by Professional Accountants: An Exploratory Study. Managerial Auditing Journal, 23(5), 504-526.

26. Jermakowicz, E., \& Rinke, D. F. (1996). The New Accounting Standards in the Czech Republic, Hungary, and Poland vis-a-vis International Accounting Standards and European Union Directives. Journal of International Accounting, Auditing and Taxation, 5(1), 73-87.

27. Khatri, J. (2011). The Economic Times.

28. Khatri, J., \& Master, A. (2009). Convergence with International Reporting Standards ('IFRS') -- Impact on Fundamental Accounting Practices and Reulatory Framework of India. Bombay Chartered Accountant Journal, 71-74.

29. Krylova, T. (2003). Accounting in the Russian Federation. Google Books.

30. Lebow, M., \& Tondkar, R. (1986). Accounting in the Soviet Union. International Journal of Accounting, 22(1), 61-79.

31. Lima, V. S., Sampaio, G. A., De Lima, F., de Cavallio, N. G., \& Lima, I. S. (2010). Toward IFRS: Economic Consequences ofAccounting Convergence in an Emerging Economy. Research in Emerging Economies, 10, 251-295.

32. Lindsay, D. (1992). Auditor-Client Conflict Resolution: An Investigation of the Perceptions of the Financial Community in Australia and Canada. International Journal of Accounting, 27, 342-365.

33. Lopes, A. B. (2006). Financial Accounting in Brazil: An Empirical Examination. Latin American Business Review, 6(4), 45-68.

34. McGee, R. W., \& Preobragenskaya, G. (2003). Problems of Implementing International Accounting Standards in a Transition Economy: A Case Study of Russia. Social Science Electronic Publishing Inc.

35. McGee, R. W., \& Preobragenskaya, G. (2006). Accounting and financial system reform in Eastern Europe and Asia. Google Books.

36. McGregor, R. (2006). China Adopts New Accounting Standards. Financial Times Web site. Retrieved May 26, 2009, from http://www.ft.com/cms/s/0/c69ba44a-9e07-11da-b641-0000779e2340.html

37. Napier, C. (1995). The History of Financial Reporting in the United Kingdom. In P. Walton, European Financial Reporting: A History (pp. 259-283). London: Academic Press.

38. Noravesh, I., Dilami, Z., \& Bazaz, M. (2007). The Impact of Culture on Accounting: Does Gray's Model Apply to Iran? Review of Accounting and Finance, 6(3), 254-272.

39. Oguri, T. (2002). A theoretical Survey of Critical Accounting Studies in Japan. Crtical Perspectives on Accounting, 13(4), 477-495.

40. O'Neill, J. (2001). Building Better Global Economic BRICs. New York: Goldman Sachs.

41. Patton, J., \& Zelenka, I. (1997). An Empirical Analysis of the Determinants of the Extent of Disclosure in Annual Reports of Joint Stock Companies in the Czech Republic. European Accounting Review, 6(4), 605626.

42. Soderstrom, N. S., \& Sun, K. J. (2007). IFRS Adoption and Accounting Quality: A Review. Accounting Review, 16(4), 675-702.

43. Sudarwan, M., \& Fogarty, T. (1996). Culture and Accounting in Indonesia: An Empirical Examination. International Journal of Accounting, 31(4), 463-481.

44. Williams, S. M., \& Tower, G. (1998). Differential Reporting in Singapore and Australia: A Small Business Manager's Perspective. 33(2), 263-268. 